\title{
Comparative Study of Alternating Low-band-Gap Benzothiadiazole Co-oligomers
}

\author{
Anna Nowakowska-Oleksy • Joanna Cabaj • \\ Kamila Olech • Jadwiga Sołoducho • Szczepan Roszak
}

Received: 21 June 2010 / Accepted: 10 January 2011 /Published online: 29 January 2011

(C) The Author(s) 2011. This article is published with open access at Springerlink.com

\begin{abstract}
The benzothiadiazole - arylene alternating conjugated oligomers have been designed and synthesized via Suzuki coupling reaction. The structures and properties of the conjugated oligomers were characterized by ${ }^{1} \mathrm{HNMR}$, ${ }^{13} \mathrm{CNMR}, \mathrm{UV}$-vis absorption spectroscopy, photoluminescence (PL) spectroscopy. The luminescent measurements demonstrate that polybenzothiadiazoles are good chromophores able to form thin films by Langmuir-Blodgett (LB) technique, making them suitable for further applications. Also the electrical properties of obtained films confirm the good potential of these novel aryl-based $\pi$-conjugated polymers for the development of various electrical and electrochemical solid-state devices.
\end{abstract}

Keywords Benzothiadiazole $\cdot$ Copolymers $\cdot$ Suzuki coupling $\cdot$ Electroconductivity $\cdot$ Luminescence $\cdot$ Atomic force microscopy

\section{Introduction}

During the past decade, organic light-emitting diodes (OLED) have been one of the most intensively explored

\footnotetext{
A. Nowakowska-Oleksy $\cdot$ J. Cabaj $\cdot$ K. Olech $\cdot$ J. Sołoducho $(\bowtie)$ Faculty of Chemistry, Department of Medicinal Chemistry and Microbiology, Wrocław University of Technology, Wybrzeże Wyspiańskiego 27,

50-370 Wrocław, Poland

e-mail: jadwiga.soloducho@pwr.wroc.pl

S. Roszak

Faculty of Chemistry, Institute of Physical and Theoretical Chemistry, Wrocław University of Technology,

Wybrzeże Wyspiańskiego 27,

50-370 Wrocław, Poland
}

topics in chemistry and applied physics owing to their wide applications in full-color displays with color filters, backlighting for liquid crystal displays, and general lighting sources [1-3]. While a large number of organic materials exhibit high fluorescence quantum efficiencies and bright in the visible region, there are some drawbacks such as low stability, high driving voltage associated with these materials. Therefore, they are not suitable for use in large area flat-panel displays. To overcome these problems and improve properties of electroluminescence (EL) devices, it is highly desirable to design and synthesize new dipolar and multifunctional materials, which could maintain well the carrier balance. П-conjugated polymers/ oligomers due to their combined desirable properties, such as fluorescence quantum yield, and good film-forming and holetransporting properties have emerged as a very promising candidate for OLEDs. Color tuning in these polymers can be achieved by incorporating an electron-deficient monomer, benzothiadiazole (BT), into the polymer backbone [4, 5]. By incorporating BT into the alkylphenothiazine or alkyl phenoxazine polymer, the resulting copolymers possessed high electron affinity and preferential electron-transporting properties. An electron-rich and electron-deficient heterocycles composing the polymers possess a dual band of absorption in the visible spectrum consisting of short- and long-wavelength absorption bands. Moreover, benzothiadiazole derivatives normally are efficient fluorophores.

Many of desirable properties of conjugated organic polymers are dependent on the material's band gap ( $\left.E_{\text {gap }}\right)$, which is energetic separation between the material's filled valence and empty conduction bands. Because of this, the significant effort has been applied to control the polymer $\mathrm{E}_{\text {gap }}$ and to produce low $\mathrm{E}_{\text {gap }}$ useful in technological fields novel materials. 
Phenothiazine, as well as phenoxazine, is well known very strong electron donor and has high HOMO energy level because of sulfur atom. In addition, the HOMO energy level of phenothiazine copolymers is dominated by contribution of phenothiazine unit. Therefore, it is expected phenothiazine ring to be an excellent building block for lowering the ionization potential of conjugated polymers. Moreover, efficient electrogenerated chemiluminescence was observed in co-oligomers of methylphenothiazine and interesting redox properties were found in other oligophenothiazines [6]. Phenothiazines as well as phenoxazines are highly nonplanar. The possible consequence of the nonplanarity of these rings for the photophysics, light-emitting properties, charge transport of $\pi$-conjugated polymers are intriguing and motivated. However, the device based on poly(alkylphenothiazine) are not enough to make efficient device since it has unbalanced charge transporting property. In order to improve electron affinity and transporting properties of material the benzothiadiazole was introduced to the oligomer backbone.

The research presented here deals with the synthesis, characterization and optical properties of novel $\pi$ conjugated oligomers based on 2,1,3-benzothiadiazole. Reported here palladium promoted coupling reaction of Suzuki is effective method of obtaining this class of highly luminescent $\pi$-extended benzothiadiazole derivatives. It is expected that these polymers could be used as air-stable conducting materials (through base doping for various electrical and electrochemical solid-states).

\section{Experimental}

Materials and Instruments

${ }^{1} \mathrm{HNMR}$ and ${ }^{13} \mathrm{CNMR}$ spectra were recorded using a Bruker 300 spectrometer. Chemical shifts are denoted in 1 unit ( $\mathrm{ppm})$ and were referenced to internal tetramethylsilane $(0.0 \mathrm{ppm})$. The splitting patterns are designated as follows: $\mathrm{s}$ (singlet), d (doublet), $\mathrm{t}$ (triplet), quin (quintet), and $\mathrm{m}$ (multiplet). Preparative column chromatography was carried out on glass columns of different sizes packed with silica gel Merck $60(40-63 \mu \mathrm{m})$. MS spectra were taken on a Bruker micrOTOF-Q, FWHM-17500, $20 \mathrm{~Hz}$. Chemical reagents were obtained from Aldrich and used as received. Tetrakis (triphenyl)phosphine palladium were obtained from Lancaster and used as received. Anhydrous THF was purified by vacuum distillation before use.

Atomic force microscopy (AFM) studies of LangmuirBlodgett films were carried out using the AFM Dimension V Veeco.

Gel Permeation Chromatography (GPC) analysis of the polymer was performed on a Waters gel permeation chromatograph with Shodex gel columns and Waters model $150 \mathrm{C}$ refractive index detectors using THF as eluent and polystyrene standards as reference.

Thermogravimetric Analysis (TGA) were conducted with a TA instrument Q50 TGA at a heating rate of $20^{\circ} \mathrm{C} / \mathrm{min}$ under nitrogen gas flow.

UV-vis absorption spectra were recorded on UV-VIS HP $8452 \mathrm{~A}$ diode array spectrophotometer in either 1 or $4 \mathrm{~cm}$ quartz cuvettes depending on the sample concentration $\left(10^{-4}-10^{-6} \mathrm{~mol} \mathrm{dm}{ }^{-1}\right)$. Emission spectra were measured at $295 \mathrm{~K}$ in $1 \mathrm{~cm}$ long-neck sealed quartz cuvettes using $90^{\circ}$ geometry on Hitachi F-2500 fluorescence spectrophotometer. All solutions were purged with $\mathrm{N}_{2}$ for 20 min prior measurement. All emission spectra were corrected using correction data obtained with rhodamine and methylene blue as quantum counters for wavelength out to $720 \mathrm{~nm}$, beyond which the response was estimated from the manufacturer's photomultiplier response data.

The luminance-current-voltage characteristics were recorded by combining the spectrometer through a Keithly model 2400 programmable voltage-current source. All the measurements were carried out at room temperature under ambient conditions.

The calculations were performed applying the DFT TD/ B3LYP method and the standard 6-31 G* atomic basis set. The results reported here were obtained by utilizing the GAUSSIAN 03 code.

\section{Supplementary Materials—-synthesis}

4,7-Dibromobenzothiadiazole (2) To a $250 \mathrm{ml}$ two-necked round bottom flask were added $5.00 \mathrm{~g}(36.72 \mathrm{mmol})$ benzothiadiazole (1) and $75 \mathrm{ml}$ of $\mathrm{HBr}(48 \%)$. A solution containing $17.47 \mathrm{~g} \mathrm{Br}_{2}(109.19 \mathrm{mmol})$ in $50 \mathrm{ml}$ of $\mathrm{HBr}$ was added dropwise very slowly (slow addition is essential!). After the total addition of $\mathrm{Br}_{2}$, the solution was heated at reflux for $6 \mathrm{~h}$. Precipitation of a dark orange solid was noted. The mixture was cooled to room temperature, and a sufficient amount of a saturated solution of $\mathrm{NaHSO}_{3}$ was added to completely consume any excess of $\mathrm{Br}_{2}$. The mixture was filtered under vacuum and washed exhaustively with water. The solid was then washed once with cold $\mathrm{Et}_{2} \mathrm{O}$ and dried under vacuum for ca. $20 \mathrm{~h} \mathrm{[7-9].}$

Data of 4,7-Dibromobenzothiadiazole $2 \mathrm{Y}=90 \%$ (9.71 g, $33.03 \mathrm{mmol}$ ), orange crystals, mp. $190{ }^{\circ} \mathrm{C},{ }^{1} \mathrm{H}$ NMR $\left(\mathrm{CDCl}_{3}\right) \delta: 7.72(\mathrm{~s}, 2 \mathrm{H}),{ }^{13} \mathrm{C}$ NMR $\left(\mathrm{CDCl}_{3}\right) \delta:$ 152.9, 132.3, 113.9.

3,7-Bis(4,4,5,5-Tetramethyl-2,1,3-Dioxaborolan-2-yl)- $\mathrm{N}$ Nonylphenoxazine (4a) To a solution of $1.00 \mathrm{~g} \mathrm{3,7-}$ dibromo- $N$-nonylphenoxazine (3a) $(2.14 \mathrm{mmol})$ in dry THF $(30 \mathrm{ml})$ at $-78{ }^{\circ} \mathrm{C}$ was added, with a syringe, 
$0.44 \mathrm{ml}(4.71 \mathrm{mmol})$ of $n$-butyllithium (2.5 M in hexane). The mixture was stirred at $-78{ }^{\circ} \mathrm{C}$, then warmed to $0{ }^{\circ} \mathrm{C}$ for $15 \mathrm{~min}$, and cooled again to $-78{ }^{\circ} \mathrm{C}$ for $15 \mathrm{~min}$. 2Isopropoxy-4,4,5,5-tetramethyl-2,1,3-dioxoborolane $1.07 \mathrm{ml}(5.25 \mathrm{mmol})$ was added rapidly to the solution, warmed to room temperature, and stirred for $24 \mathrm{~h}$. The mixture was poured into water and extracted with diethyl ether. The organic layers were washed with brine, and dried over magnesium sulfate. The solvent was removed, and the residue was purified by column chromatography with hexane:ethyl acetate $(1: 1)$ as eluent $[10,11]$.

Data of 3,7-Bis(4,4,5,5-Tetramethyl-2,1,3-Dioxaborolan-2$y l$ )-N-Nonylphenoxazine 4a $\mathrm{Y}=64 \%(0.79 \mathrm{~g}, 1.37 \mathrm{mmol})$, yellowish crystals, mp. $88{ }^{\circ} \mathrm{C},{ }^{1} \mathrm{H}$ NMR $\left(\mathrm{CDCl}_{3}\right) \delta: 7.26-$ 7.23 (m, $2 \mathrm{H}$, arom. H), 6.98-6.83 (m, $2 \mathrm{H}$, arom. H), 6.29 (s, $2 \mathrm{H}$, arom. H), 3.45-3.40 (m, $\left.2 \mathrm{H}, \mathrm{CH}_{2}\right), 1.56-1.41$ (m, $\left.8 \mathrm{H}, \mathrm{CH}_{2}\right), 1.35-1.27\left(\mathrm{~m}, 24 \mathrm{H}, \mathrm{CH}_{3}\right), 1.24-1.23(\mathrm{~m}, 6 \mathrm{H}$, $\left.\mathrm{CH}_{2}\right), 0.88$ (t, $\left.3 \mathrm{H}, J=6.71 \mathrm{~Hz}, \mathrm{CH}_{3}\right) .{ }^{13} \mathrm{C} \mathrm{NMR}\left(\mathrm{CDCl}_{3}\right) \delta$ : 145.26, 132.25, 127.80 (2 C linked to boron, broad peak), $126.57,118.61,112.46,112.23,44.31,31.86,29.56,29.38$, $29.24,26.86,24.73,22.68,14.12$.

3,6-Bis(4,4,5,5-Tetramethyl-2,1,3-Dioxaborolan-2-yl)- $N$ Octylphenothiazine (4b) To a solution of $3.02 \mathrm{~g} \mathrm{3,7-}$ dibromo- $N$-octylphenothiazine (3b) $(6.44 \mathrm{mmol})$ in dry THF $(30 \mathrm{ml})$ at $-78^{\circ} \mathrm{C}$ was added, with a syringe, $1.31 \mathrm{ml}$ (14.16 mmol) of $n$-butyllithium (2.5 $\mathrm{M}$ in hexane). The mixture was stirred at $-78{ }^{\circ} \mathrm{C}$, then warmed to $0{ }^{\circ} \mathrm{C}$ for $15 \mathrm{~min}$, and cooled again to $-78{ }^{\circ} \mathrm{C}$ for $15 \mathrm{~min}$. 2Isopropoxy-4,4,5,5-tetramethyl-2,1,3-dioxoborolane $3.22 \mathrm{ml}(15.77 \mathrm{mmol})$ was added rapidly to the solution, warmed to room temperature, and stirred for $24 \mathrm{~h}$. The mixture was poured into water and extracted with diethyl ether. The organic layers were washed with brine, and dried over magnesium sulfate. The solvent was removed, and the residue was purified by column chromatography with hexane:ethyl acetate $(1: 1)$ as eluent $[10,11]$.

Data of 3,7-bis(4,4,5,5-Tetramethyl-2,1,3-Dioxaborolan-2$y l)$-N-Octylphenothiazine $4 \mathbf{b} \mathrm{Y}=45 \%(1.68 \mathrm{~g}, 2.90 \mathrm{mmol})$, yellow-white oil, ${ }^{1} \mathrm{H} \mathrm{NMR}\left(\mathrm{CDCl}_{3}\right) \delta: 6.84(\mathrm{~d}, J=8.3 \mathrm{~Hz}$, $2 \mathrm{H}$, arom. H), 6.52 (d, J=3.2 Hz, $2 \mathrm{H}$, arom. H), 6.44 (dd, $J=3.2 \mathrm{~Hz}, J=1.7 \mathrm{~Hz}, 2 \mathrm{H}$, arom. H), 3.85 (t, $J=7.1 \mathrm{~Hz}$, $\left.2 \mathrm{H}, \mathrm{CH}_{2}\right), 1.81-1.79\left(\mathrm{~m}, 2 \mathrm{H}, \mathrm{CH}_{2}\right), 1.35-1.27(\mathrm{~m}, 24 \mathrm{H}$, $\left.\mathrm{CH}_{3}\right), 1.25-1.23\left(\mathrm{~m}, 10 \mathrm{H}, \mathrm{CH}_{2}\right), 0.83(\mathrm{t}, J=6.3 \mathrm{~Hz}, 3 \mathrm{H}$, $\left.\mathrm{CH}_{3}\right) .{ }^{13} \mathrm{C}$ NMR $\left(\mathrm{CDCl}_{3}\right)$ 8: 153.2, 143.9, $127.80(2 \mathrm{C}$ linked to boron, broad peak), 125.6, 124.5, 122.9, 122.7, $115.3,111.8$. 111.5, 103.8, 47.6, 31.8, 29.5, 28.0, 27.6, $26.8,22.6,14.0$.

Poly[(N-Nonylphenoxazine-3,7-Diyl-alt-(2,1,3-Benzothiadiazole)] (5a) The following general Suzuki polymeriza- tion procedure was used for the preparation of all the copolymers. To a three-necked flask $0.20 \mathrm{~g} 3,7$-bis(4,4,5,5tetramethyl-2,1,3-dioxaborolan-2-yl)- $N$-nonylphenoxazine (4a) $(0.35 \mathrm{mmol}), 0.10 \mathrm{~g} \mathrm{4,7-dibromobenzothiadiazole} \mathrm{(2)}$ $(0.35 \mathrm{mmol}), 0.01 \mathrm{~g} \mathrm{Pd}\left(\mathrm{PPh}_{3}\right)_{4}(4.80 \mu \mathrm{mol})$, and $0.57 \mathrm{~g}$ potassium carbonate $(0.04 \mathrm{mmol})$ was added. A mixture of water $(0.21 \mathrm{ml})$ and toluene $(15 \mathrm{ml})$ was added to the flask, and the reaction vessel was degassed. The mixture was heated at $90{ }^{\circ} \mathrm{C}$ for $24 \mathrm{~h}$ under nitrogen and then precipitated into methanol. The polymer was filtered and washed with methanol and acetone and then dried under vacuum overnight to afford the neutral oligomer $[12,13]$.

Data of Poly[(N-Nonylphenoxazine-3,7-Diyl-alt-(2,1,3Benzothiadiazole)] (5a) Y $=45 \%(0.05 \mathrm{~g}, 0.16 \mathrm{mmol})$, dark brown crystals, ${ }^{1} \mathrm{H}$ NMR $\left(\mathrm{CDCl}_{3}\right) \delta: 7.87(\mathrm{~d}, 2 \mathrm{H}, J=$ $7.68 \mathrm{~Hz}$, arom. H), 7.73 (s, $2 \mathrm{H}$, arom. H), 6.85-6.83 (m, $2 \mathrm{H}$, arom. H), 6.34 (d, $2 \mathrm{H}, J=8.57 \mathrm{~Hz}$, arom. H), 3.45-3.40 (m, $\left.2 \mathrm{H}, \mathrm{CH}_{2}\right), 1.56-1.25\left(\mathrm{~m}, 14 \mathrm{H}, \mathrm{CH}_{2}\right), 0.88(\mathrm{t}, 3 \mathrm{H}, J=$ $\left.6.71 \mathrm{~Hz}, \mathrm{CH}_{3}\right) .{ }^{13} \mathrm{C}$ NMR $\left(\mathrm{CDCl}_{3}\right) \delta: 132.28,128.00$, $126.67,126.29,124.99,118.53,115.83,112.44,111.38$, $44.16,31.80,29.52,29.35,29.20,26.85,24.83,22.62,14.07$.

Poly[(N-Octylphenothiazine-3,7-Diyl-alt-(2,1,3-Benzothiadiazole)] (5b) To a three-necked flask $2.92 \mathrm{~g} \mathrm{3,7-bis(4,4,5,5-}$ tetramethyl-2,1,3-dioxaborolan-2-yl)- $N$-octylphenothiazine (4b) $(5.45 \mathrm{mmol}), 1.60 \mathrm{~g} \mathrm{4,7-dibromobenzothiadiazole} \mathrm{(2)}$ (5.45 mmol), $0.09 \mathrm{~g} \mathrm{Pd}\left(\mathrm{PPh}_{3}\right)_{4}(75.46 \mu \mathrm{mol})$, and $9.04 \mathrm{~g}$ potassium carbonate $(65.40 \mathrm{mmol})$ was added. A mixture of water $(32.7 \mathrm{ml})$ and toluene $(15 \mathrm{ml})$ was added to the flask, and the reaction vessel was degassed. The mixture was heated at $90{ }^{\circ} \mathrm{C}$ for $24 \mathrm{~h}$ under nitrogen and then precipitated into methanol. The polymer was filtered and washed with methanol and acetone and then dried under vacuum overnight to afford the neutral oligomer $[12,13]$.

Data of Poly[(N-Octylphenothiazine-3,7-Diyl-alt-(1,2,3Benzothiadiazole)] (5b) Y=57\% (1.03 g, $2.96 \mathrm{mmol})$, brown crystals, ${ }^{1} \mathrm{H}$ NMR $\left(\mathrm{CDCl}_{3}\right) \delta: 7.64(\mathrm{~s}, 2 \mathrm{H}$, arom. H), 7.24-7.09 (m, $4 \mathrm{H}$, arom. H), 6.64 (d, $2 \mathrm{H}, J=8.39 \mathrm{~Hz}$, arom. H), 3.74-3.69 (m, $\left.2 \mathrm{H}, \mathrm{CH}_{2}\right), 1.78-1.67(\mathrm{~m}, 10 \mathrm{H}$, $\left.\mathrm{CH}_{2}\right), 1.40-1.24\left(\mathrm{~m}, 10 \mathrm{H}, \mathrm{CH}_{2}\right), 0.90(\mathrm{t}, 3 \mathrm{H}, J=5.37 \mathrm{~Hz}$,

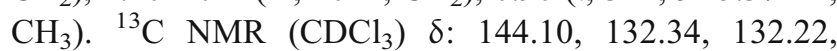
$132.09,132.00,130.13,129.67,128.63,128.47,127.40$, $127.18,126.43,122.29,116.66,115.39,114.76,113.93$, $47.65,31.77,29.44,29.23,27.03,26.96,22.78,14.18$.

\section{Results and Discussion}

The synthesis of dibromobenzothiadiazole is outlined in Scheme 1. The reaction of $\mathbf{1}$ with molecular bromine (added 


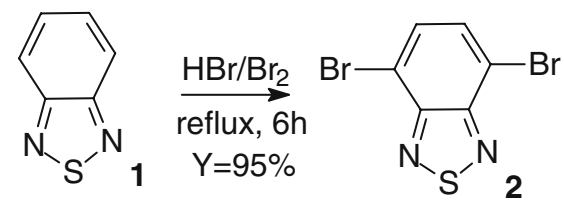

Scheme 1 Synthesis of dibromobenzothiadiazole

dropwise very slowly) in hydrobromic acid exclusively affords 4,7-dibromobenzothiadiazole (2) as a major product in $95 \%$ yield (Scheme 1) [7].

The synthesis of oligomers $\mathbf{5 a}-\mathbf{b}$ was provided as shown in Scheme 2. Conversion of $N$-alkyl-3,7-dibromo- $N$-alkylphenoxazine (3a), -phenothiazine (3b) to the boronic ester (4a-b) was achieved (according to literature general procedure [8]) under reaction conditions in presence 2isopropoxy-4,4,5,5-tetramethyl-1,3,2-dioxaborolane. Compounds $4 \mathbf{a}-\mathbf{b}$ underwent Suzuki palladium-catalyzed polycondensation. Alternated DA oligomers $\mathbf{5 a}-\mathbf{b}$ were obtained in $50 \%$ yield after purification by silica column chromatography. The molar ratio of phenoxazine moiety in the oligomers was controlled by adjusting the molar ratio between dibromobenzothiadiazole and monomers $4 \mathbf{4}-\mathbf{b}$ while a 1/1 molar ratio between the dibromides and the bisborylated compounds was maintained.

The structures of the obtained co-oligomers were confirmed by ${ }^{1} \mathrm{HNMR},{ }^{13} \mathrm{CNMR}$ as well as MS spectroscopy. All structures were found to be highly soluble in most of organic solvents such as methylene chloride, chloroform, toluene, and $o$-dichlorobenzene.

GPC analysis was used to estimate the molecular weight of each sample. The molecular weight data are summarized in Table 1. It was determined that the oligomers were all of rather low molecular weight. Both oligomers gave numberaverage molecular weights of about $3,500 \mathrm{~g} / \mathrm{mol}$. This value corresponds to a degree of polymerization of seven to eight, meaning that the polymers synthesized here have an average of about 30 aromatic rings per chain. The
Table 1 Summary of GPC data (polystyrene standard) for benzothiadiazole co-oligomers

\begin{tabular}{lcccc}
\hline Polymer & $\mathrm{M}_{\mathrm{n}}[\mathrm{g} / \mathrm{mol}]$ & $\mathrm{M}_{\mathrm{w}}[\mathrm{g} / \mathrm{mol}]$ & $\mathrm{T}_{\mathrm{g}}\left[{ }^{\circ} \mathrm{C}\right]$ & $\mathrm{PDI}$ \\
\hline $\mathbf{5 a}$ & 3,500 & 5,200 & 130 & 1.57 \\
$\mathbf{5 b}$ & 3,600 & 5,400 & 80 & 1.62 \\
\hline
\end{tabular}

molecular weights obtained were adequate for processing and film formation, and thus, further optimization of the polymerization was not attempted. The average molecular weight $\left(M_{w 5 \mathbf{a}-\mathbf{b}}\right)$ of the copolymers was determined by gel permeation chromatography against polystyrene standards in THF (polydispersity in every case near 1.6).

Thin Films Formation

Thin films of these compounds were also easily fabricated from their solutions in chloroform by Langmuir-Blodgett (LB) technique.

Synthesized oligomers 5a-b dissolved in organic solvents (chloroform) were spread on the water, then organic layers were deposited by LB technique onto ITO $(50 \Omega)$ or a set of eight interdigital, buried $\mathrm{Au}$ electrodes $(200 \mu \mathrm{m}$ wide and spaced) photolithographically fixed on $\mathrm{SiO}_{2}$ thermally coated silicon substrates. Etching canals in silicone substrates were then filling by mixture of gold and trace amount of wolfram. This configuration provides flat, polished (measured by interferometric method) electrodes, ready to LB deposition. All initially non measured under water films were deposited at the velocity lower than the draining rate of film of carboxylic acids i.e. $1.3 \mathrm{~mm} /$ min. After deposition, films were stored in vacuum dessicator prior to use.

Langmuir monomolecular films of $\mathbf{5 a - b}$ were spread from $\mathrm{CHCl}_{3}$ solution on high purity water at room temperature. Langmuir-Blodgett deposition was carried
Scheme 2 Synthetic route to the co-oligomers based on benzothiadiazole

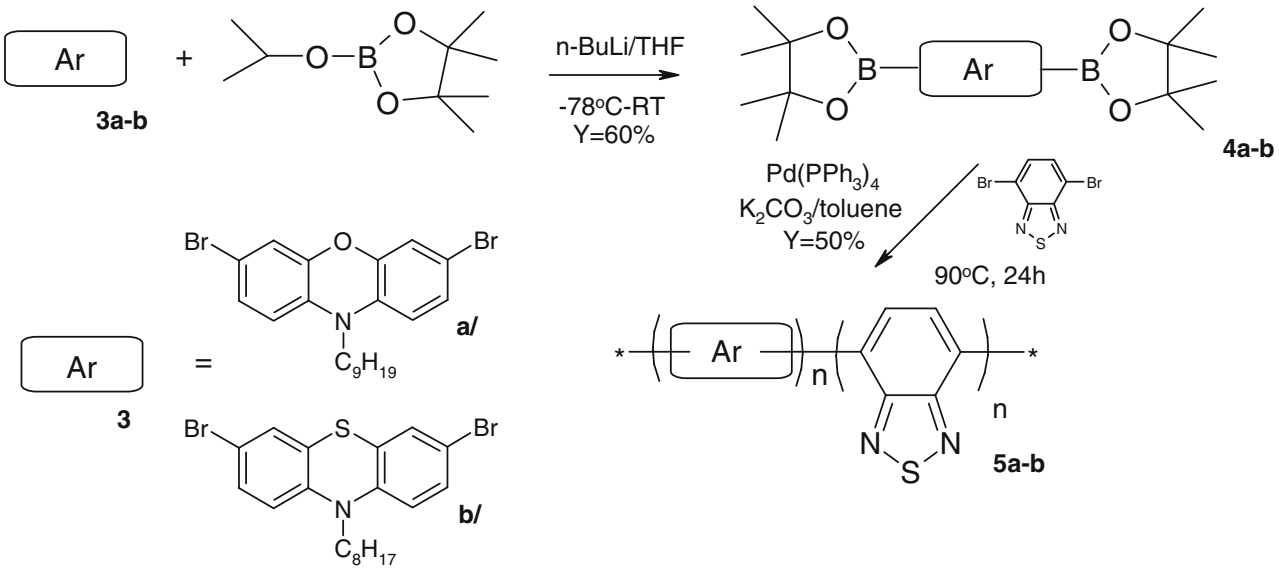


out with a KSV System 5000 LB through at a surface pressure of around $20-25 \mathrm{mN} / \mathrm{m}$.

The sample processing was carried out at $c a .22{ }^{\circ} \mathrm{C}$ as well as conductivity measurements. The transference of LB film was $\mathrm{Y}$-type in first deposition. The relationship between absorbance and number of layers and constant transfer ratio during the deposition indicate on constant architecture of LB film layers.

The LB film morphology was examined using atomic force microscopy. Experimental results on the topography (Fig. 1) show that the LB film is compact and highly ordered. On Fig. 1, for comparison, is also shown the topography of clean substrate (glass slide, Fig. 1b) before oligomer deposition. The high degree of homogeneity is observed for the film 5a. The surface roughness is rather smooth, it is due the reorganization of oligomer molecules during the LB deposition. The value of average roughness equals $9.8 \mathrm{~nm}$. No clear crystalline fibers were observed in the AFM images.

The major result of investigations was pointed on the electrical conductivity of Langmuir-Blodgett (LB) films consisting several layers of synthesized compound (5a) as an effective conducting material.

Figure 2 shows typical current-voltage (I-V) curves of fabricated LB films at room temperature. The I-V curves are asymmetrical and non-linear. The forward currents follow approximately an exponential trend. This I-V behaviour is connected with diode-like type conductivity. The conductivity found for oligomer 5a LB film equals $\sigma=$ $1.2 \times 10^{-4} \mathrm{~S} / \mathrm{m}$.

From current-voltage characteristics obtained at higher temperatures $\left(60{ }^{\circ} \mathrm{C}, 80{ }^{\circ} \mathrm{C}\right)$, it was found that the characteristics of the $\mathrm{I}-\mathrm{V}$ maintain its asymmetrical shape and character. The forward currents increase strongly with increasing voltage.

Therefore, these results indicate that obtained films behave as p-type semiconductors. Moreover, good environ- mental stabilities observed for this material makes it a promising candidate for sensing elements.

Figure 3 displays the voltage-luminance results of compound 5a. The maximum luminance brightness is $6,857 \mathrm{~cd} \mathrm{~m}^{-2}$ at $11 \mathrm{~V}$. The brightness of $\mathbf{5 a}$ is improved largely, which denotes that compound has good holetransporting ability and luminance property.

Figure 4 illustrated the luminance efficiency at different voltages. As the voltages increased gradually, the maximum luminescent efficiency increased to $3.10 \mathrm{~cd} \mathrm{~A}^{-1}$. This phenomenon is a consequence of the formation of excitons required to emit light.

\section{Optical Properties}

While the origin of the dual-band absorption sometimes encountered in DA-type semiconducting polymers remains a source of debate, two mainstream rationales have been frequently proposed. A first assumption attributes the lower-energy optical transition to the presence of intermolecular charge-transfer excitons occurring on the presence of covalently bound DA segments along the backbone. A second assumption considers the presence of low-lying unoccupied energy levels, strictly localized on the electrondeficient heterocycles, yet forming a discrete "band" of easily accessed energy states within the bandgap of the conjugated system in its ground state. In both cases, the higher-energy transitions appear localized on the mostelectron-rich building units incorporated along the polymer backbone with a clear dependence on their relative concentration to the electron-deficient heterocycles.

This distinct contribution from the electron-rich segments on the short-wavelength absorption band in DA backbones As well, the long-wavelength absorption band (red shifted) is illustrated in Figure 5.

The photophysical characteristic of the copolymers (5a-b) were investigated by ultraviolet-visible (UV-vis)

Fig. 1 Surface morphology (AFM) of LB 5a film (20 layers) on glass slide (a); image of the bare glass (b)

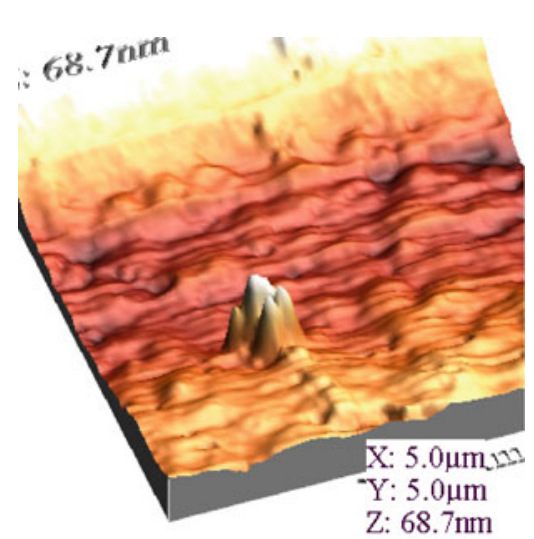

a

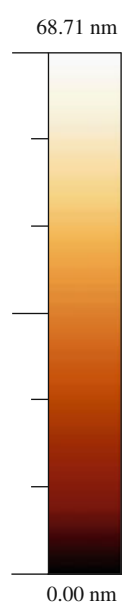

$0.00 \mathrm{~nm}$

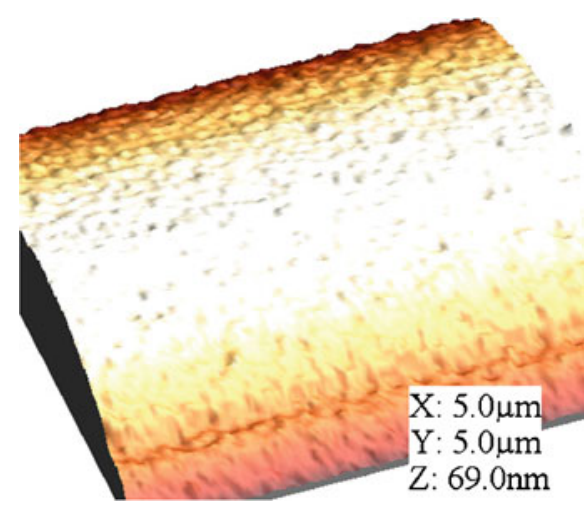

b 

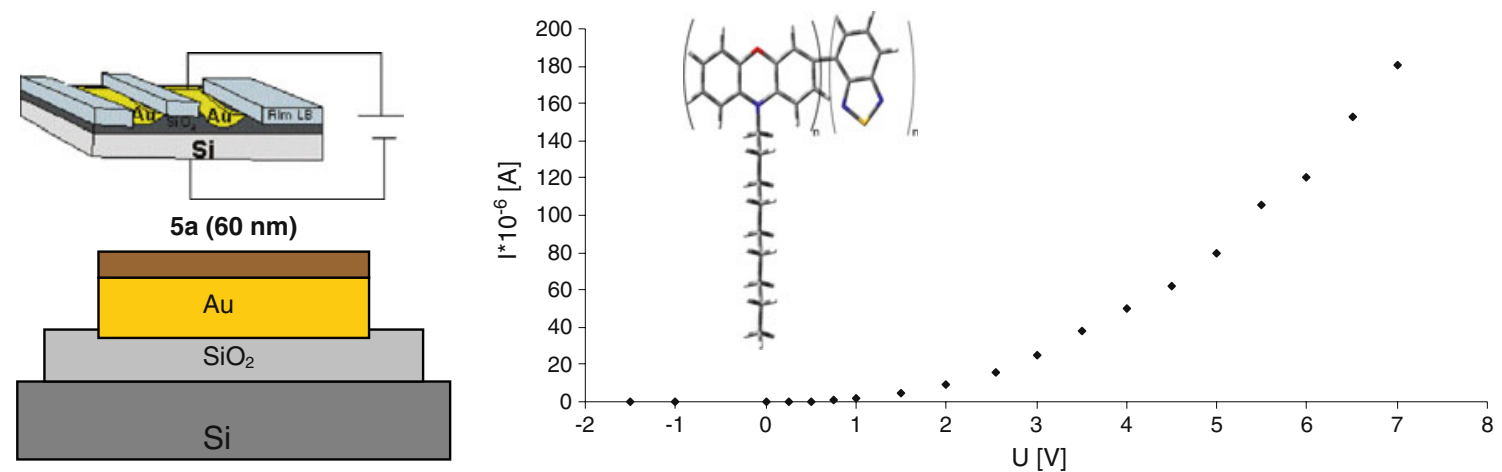

Fig. 2 The current-voltage characteristics of 20 layer LB film built of poly[( $N$-nonylphenoxazine-3,7-diyl-alt-(2,1,3-benzothiadiazole)] (5a) and measuring system (left)

absorption and photoluminescence (PL) in diluted chloroform solution and in solid state. The optical data summarized are also listed in Table 2. A plot of extinction coefficient versus wavelength for the compound as measure in chloroform is depicted in Figure 5. As expected, 5a-b exhibit a dual band of absorption, in this case peaking at $280,425 \mathrm{~nm}$ and $280,400 \mathrm{~nm}$ for $\mathbf{5 a}-\mathbf{b}$, respectively. 2,1,3-Benzothiadiazole adsorbs at $306 \mathrm{~nm}$ [14]. It should be noted that the absorption bands characteristic for phenoxazine ring are localized at about $400 \mathrm{~nm}$. However, the extent of conjugation between neighbouring benzothiadiazole units and phenoxazine ones will largely depend on the twist angle. The above data clearly suggest that the corresponding polymer has potential as low-band-gap material. The UV-vis spectrum of $\mathbf{5 b}$ is very similar to spectrum of $\mathbf{5 a}$, but there is very characteristic broad absorption at $490-510 \mathrm{~nm}$ in solid state which was found also in another compounds based on benzothiadiazole and $N$-alkylphenothiazine (poly $(3,7-$ divinylene- $N$-octylphenothiazine-alt-benzothiadiazole)

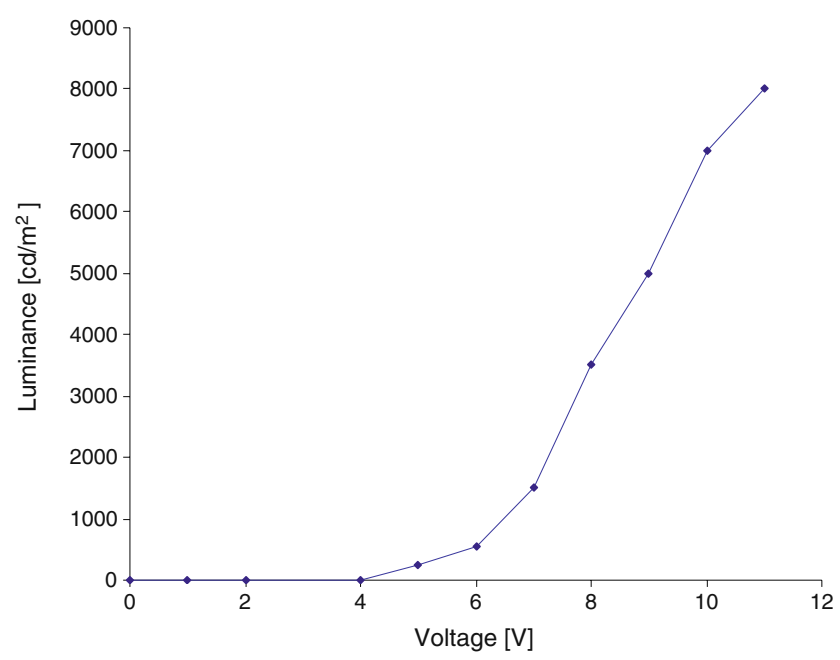

Fig. 3 The voltage-luminance curves of compound 5a as LB film
[15]). Similar donor-acceptor interaction between the electron-poor benzothiadiazole unit and the relatively electron-rich unit $\lambda_{\max }$ at $460 \mathrm{~nm}$, leading to an orange colour was found also in case of carbazole - benzothiadiazole copolymers [16].

In general, the absorption range of solid of $\mathbf{5 a}$ and $\mathbf{5 b}$ is slightly red-shifted than those of solution because of the formation of aggregates (Fig. 5). However, the absorption range of polyphenothiazine and $\mathbf{5 b}$ are not much different, this is due to that phenothiazine impede formation of aggregates in the solid state [17].

The photoluminescent properties of the synthesized oligomers $(\mathbf{5 a}-\mathbf{b})$ were investigated by fluorescence spectroscopy in dilute chloroform solution $(2 \mu \mathrm{M})$. The fluorescence quantum yield of the oligomers $\mathbf{5 a}-\mathbf{b}$ were rather $\operatorname{good}\left(\mathbf{5} \mathbf{a}-\varphi_{\mathrm{f}}=0.42, \mathbf{5 b}-\varphi_{\mathrm{f}}=0.48\right)$. The fluorescence quantum yield of benzothiadiazole is very low $\left(\varphi_{\mathrm{f}}=\right.$ 0.006). Molecules 5a and 5b have rather large Stokes' shifts, $162\left(61728 \mathrm{~cm}^{-1}\right)$ and $145 \mathrm{~nm}\left(68965 \mathrm{~cm}^{-1}\right)$ respectively.

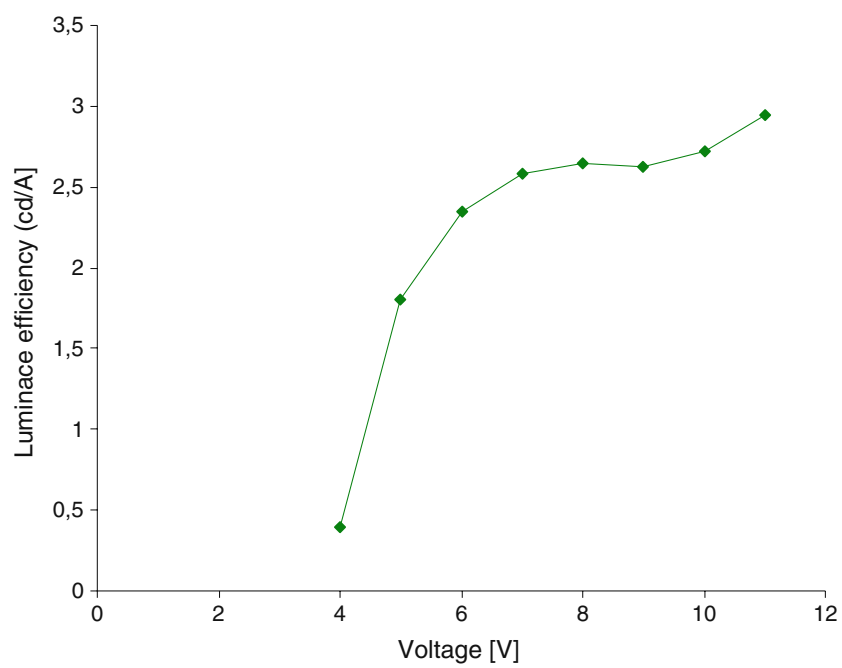

Fig. 4 The voltage-efficiency curves of compound 5a as LB film 

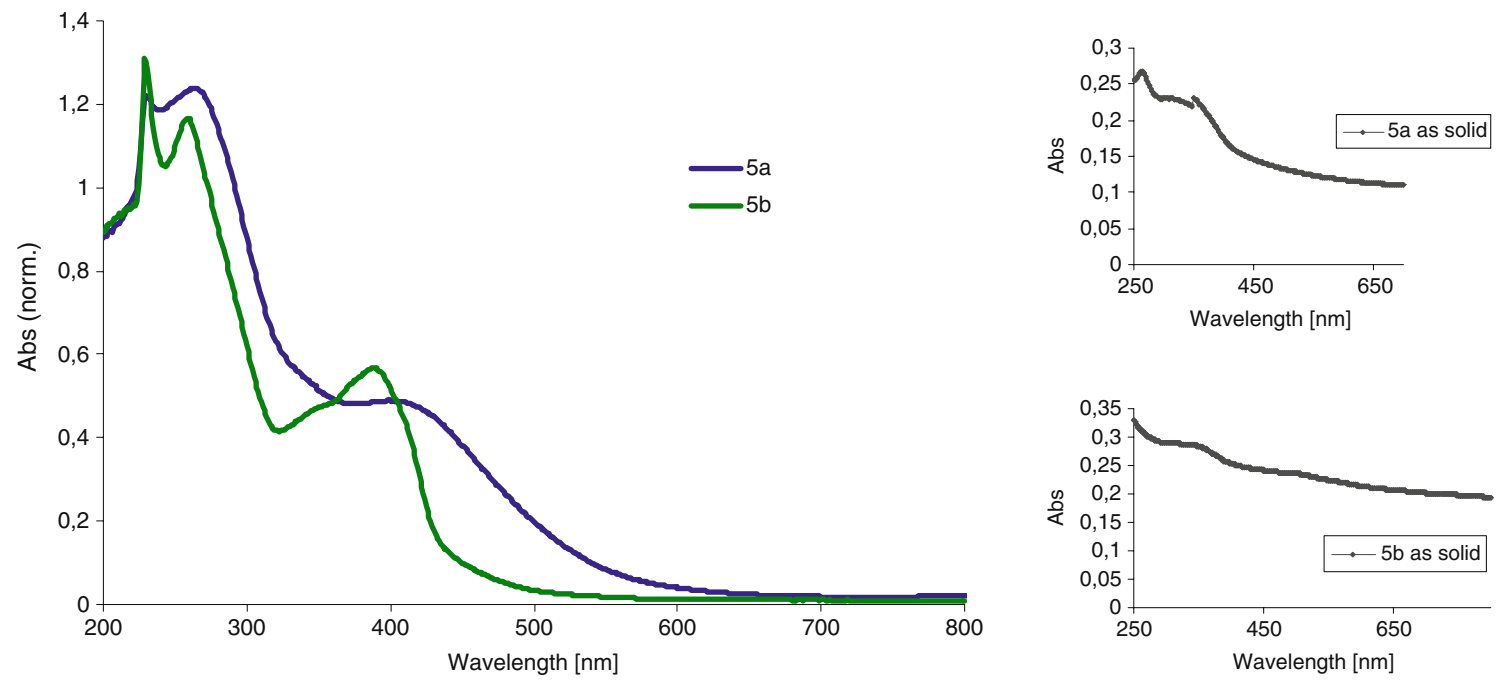

Fig. 5 UV-visible absorption spectra of polymers $\mathbf{5 a}$ and $\mathbf{5 b}$ in chloroform diluted solution $(2 \mu \mathrm{M})$, as insert absorption spectra of $\mathbf{5 a}$ and $\mathbf{5 b}$ in the solid state

The emission spectra of $\mathbf{5 a}$ and $\mathbf{5 b}$ solution were recorded at different excitation wavelengths in the range 310-390 nm, but the emission values were almost the same. The phenoxazine/phenothiazine - benzothiadiazole based oligomer emits in the blue region. However, when excited diluted solution of $\mathbf{5 a}$ at $389 \mathrm{~nm}$ the emission was centred at $476 \mathrm{~nm}$ (2.61 eV, Fig. 6, Table 2). In case of $\mathbf{5 b}$ the emission maximum was found at $480 \mathrm{~nm}$ (2.58 eV, Fig. 7). The observed Stokes shift according to phenoxazine emission suggests that there is a large twist between benzothiadiazole and neighbouring aromatic units.

The luminescence emission spectrum of $\mathbf{5 a}$ has well resolved vibronic structrures in dilute chloroform solution. The emission spectrum of $\mathbf{5 a}$ has a vibronic progression with the $0-0$ transition at $476 \mathrm{~nm}$. Incorporation of benzothiadiazole moieties into polyphenoxazine results in a slight red shift in the $0-0$ in the emission band from $458 \mathrm{~nm}$ (polyphenoxazine) [12] to $476 \mathrm{~nm}$, both polyphenoxazine and polyphenoxazine with incorporated benzothiadiazole emits blue light in diluted solutions.
2,1,3-Benzothiadiazole - based oligomers and polymers have been widely studied in recent years as active materials in various optoelectronic devices because of the heterocyclic group and the observed low-band-gap in polymers containing it [18]. Copolymerization of benzothiadiazole with phenoxazine, phenothiazine, fluorene [4] and carbazole [16] or other suitable arylenes can be used as a means to tune the HOMO - LUMO levels in the resulting polymers. The HOMO and LUMO energy level of $\pi$-conjugated polymer are important for understanding charge injection processes in the luminescent devices.

By the theoretical study the luminescence of benzothiadiazole - phenoxazine oligomer (5a) was found as $506 \mathrm{~nm}$ (Table 2), in case of $\mathbf{5 b}$ the value is $482 \mathrm{~nm}$. The above data, similar to experimental $(476 \mathrm{~nm}-\mathbf{5 a}, 480 \mathrm{~nm}-\mathbf{5 b})$, clearly suggests that the corresponding copolymers has potential as low-band-gap materials. The low optical band gaps of the oligomers should result from the alternating between the electron-rich unit of alkylphenothiazine/alkylphenoxazine and the strong electron-deficient unit of

Table 2 Summary of physical properties of benzothiadiazole co-oligomers

\begin{tabular}{|c|c|c|c|c|c|c|c|}
\hline \multirow[t]{2}{*}{ Polymer } & \multicolumn{4}{|l|}{ In solution } & \multirow{2}{*}{$\begin{array}{l}\text { In solid state } \\
\text { abs } \lambda_{\max }[\mathrm{nm}]\end{array}$} & \multirow[t]{2}{*}{ Egap $^{\mathrm{b}}[\mathrm{eV}]$} & \multirow[t]{2}{*}{$\operatorname{Egap}^{\mathrm{c}}[\mathrm{eV}]$} \\
\hline & $\operatorname{abs} \lambda_{\max }[\mathrm{nm}]$ & PL $\lambda_{\max }{ }^{a}[\mathrm{~nm}]$ & Stokes shift $\left[\mathrm{cm}^{-1}\right]$ & $\varphi_{\mathrm{f}}$ & & & \\
\hline $5 \mathbf{a}$ & 280 & 476 & 61728 & 0.42 & 355 & 2.45 & 2.61 \\
\hline $5 b$ & 284 & 480 & 68965 & 0.48 & 360,500 & 2.57 & 2.58 \\
\hline
\end{tabular}

${ }^{\text {a }}$ polymer in chloroform solution was excited at $389 \mathrm{~nm}$

$\mathrm{b}$ theoretical data

${ }^{\mathrm{c}}$ figured out from the absorption edge from the PL spectrum 
Fig. 6 The PL spectra of 5a in chloroform diluted $(2 \mu \mathrm{M})$ solution

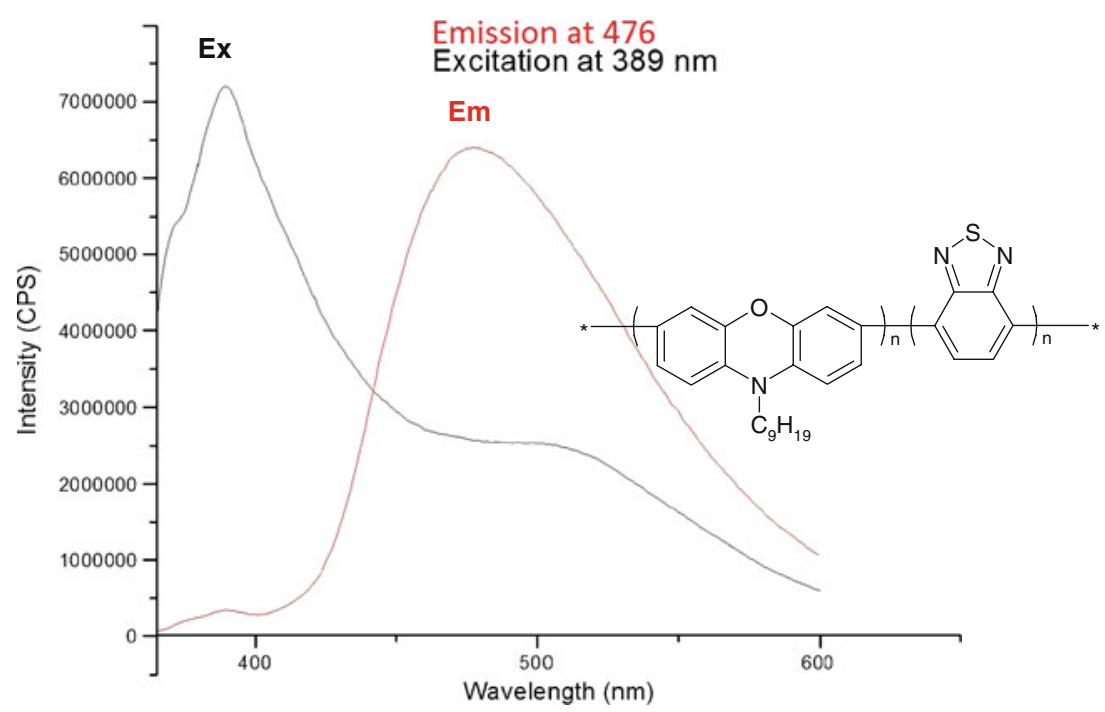

benzothiadiazole. The application of these oligomers are currently being investigated.

\section{Conclusions}

In summary, according to the donor-acceptor-alternating strategy, this paper described the synthesis of novel $\pi$ conjugated co-oligomers based on benzothiadiazole structure through well-known palladium catalyzed Suzuki polycondensation. The ability of connection of electron-donating and electron-withdrawing groups in benzothiadiazole cooligomers, has been applied to developing methods for controlling the polymer $\mathrm{E}_{\text {gap }}$ and producing technologically useful low-band-gap conjugated materials. The use of electron-withdrawing groups, however, provides reduced HOMO-LUMO energies and lower $\mathrm{E}_{\text {gap }}$ values. The application of such alternating co-oligomers employing electron-withdrawing groups appears to be a promising new approach for the production of low $\mathrm{E}_{\text {gap }}$ materials.

The obtained semiconducting oligomers - bifunctional materials as viable luminance and high hole-transporting one, exhibit excellent solubility in common organic solvents, thermal stability and luminescence in blue region and can be cast into uniform films. They possess good fluorescence quantum. The band gap values of synthesized compounds are in the adequate range $(2.54-2.75 \mathrm{eV})$ for testing as OLEDs. Thin, ordered film fabricated of these compounds were found as semiconducting material for diode application.

Furthermore, it must be emphasized that benzothiadiazolebased copolymers have not only good processability due to the backbone, in which alkyl groups are incorporated, but also bright and uniform luminescence in the visible region. Since stable, bright blue emission is still a limiting factor in high performance LED devices. Polymers with these unique
Fig. 7 The PL spectra of $5 b$ in chloroform diluted $(2 \mu \mathrm{M})$ solution

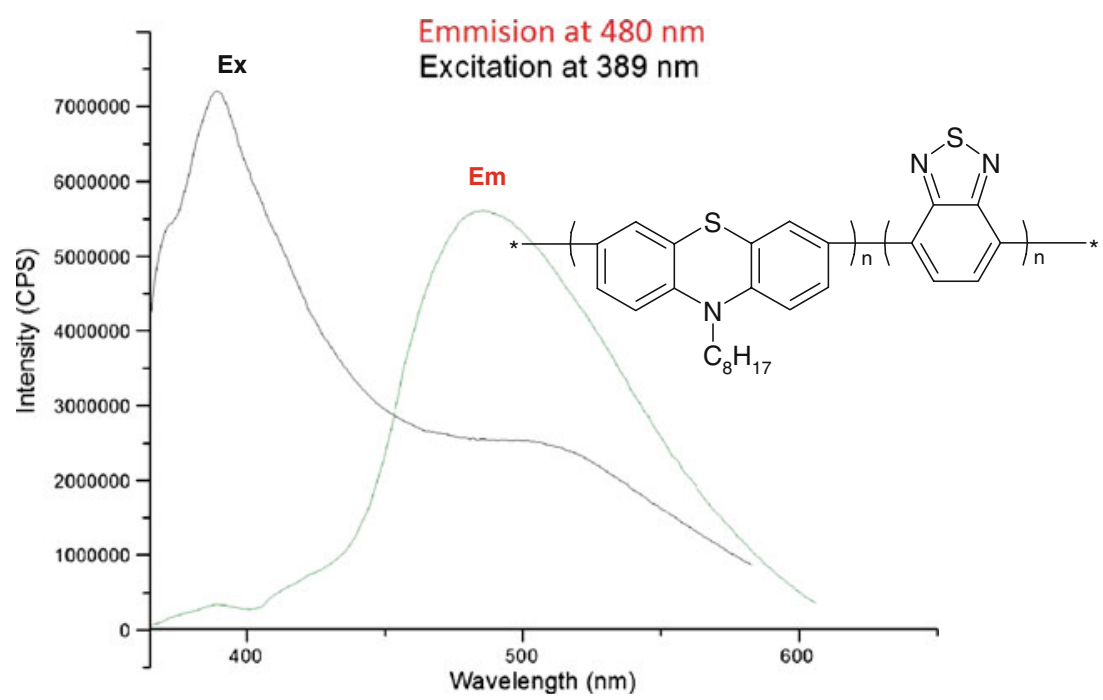


backbones will be able to be introduced in many applications for low cost electronics, which needs good reproducibility of device performance and moderate field-effect mobility.

Acknowledgments Authors are acknowledged to Wrocław University of Technology and to the Polish Ministry of Science and Higher Education (Grant No. NN 204 244934) for financial support.

Open Access This article is distributed under the terms of the Creative Commons Attribution Noncommercial License which permits any noncommercial use, distribution, and reproduction in any medium, provided the original author(s) and source are credited.

\section{References}

1. Ouyang XH, Zeng HP, Ding GY, Jiang WL, Li J (2009) Luminance materials containing carbazole and triphenylamine exhibiting high hole-transporting properties. Synth Met 159:2063-2069

2. Kanno H, Sun Y, Forrest SR (2005) High efficiency top-emissive white light emitting electrophosphorescent devices. Appl Phys Lett 86:263502-263504

3. Lu YJ, Chang CH, Lin CL, Wu CC, Hsu HL, Chen LJ, Lin YT, Nishikawa R (2008) Achieving three-peak white organic lightemitting devices using wavelength-selective mirror electrodes. Appl Phys Lett 92:123303-123305

4. Herguth P, Jiang X, Liu MS, Jen AKY (2002) Highly efficient fluorene- and benzothiadiazole-based conjugated copolymers for polymer light-emitting diodes. Macromolecules 35:6094-6100

5. Donat-Bouillud A, Lévesque I, Tao Y, D’Iorio M, Beaupré S, Blondin P, Ranger M, Bouchard J, Leclerc M (2000) Lightemitting diodes from fluorene-based $\pi$-conjugated polymers. Chem Mater 12:1931-1936

6. Choi J, Lee B, Kim JH (2009) Synthesis and electroluminescent properties of $\pi$-conjugated copolymer based on 10 hexylphenothiazine and aromatic 1, 2, 4-triazole. Synth Met 159:1922-1927

7. DaSilveira-Neto BA, Lopes A, Ebeling G, Gonçalves R, Costa VEU, Quina FH, Dupont J (2005) Photophysical and electrochemical properties of pi-extended molecular 2, 1, 3-benzothiadiazoles. Tetrahedron 61:10975-10982

8. Mancilha FS, DaSilveira-Neto BA, Lopes AS, Moreira PF, Quina FH, Gonçalves R, Dupont J (2006) Are molecular 5, 8- extendedquinoxaline derivatives good chromophores for photoluminescence applications? Eur J Org Chem 12:4924-4933

9. DaSilvera-Neto BA, Lopes AS, Wüst M, Costa VEU, Ebeling G, Dupont J (2005) Reductive sulfur extrusion reaction of 2, 1, 3benzothiadiazole compounds: a new methodology using NaBH4/ $\mathrm{CoCl} 2.6 \mathrm{H} 2 \mathrm{O}$ (cat) as the reducing system. Tetrahedron Lett 46:6843-6846

10. Willis DM, Strongin RM (2000) Palladium-catalyzed borylation of aryldiazonium tetrafluoroborate salts: a new synthesis of arylboronic esters. Tetrahedron Lett 41:8683-8686

11. Ranger M, Leclerc M (1999) New base-doped polyfluorene derivatives. Macromolecules 32:3306-3313

12. Zhu Y, Champion RD, Jenekhe SA (2006) Conjugated donoracceptor copolymer semiconductors with large intramolecular charge transfer: synthesis, optical properties, electrochemistry, and field effect carrier mobility of thienopyrazine-based copolymers. Macromolecules 39:8712-8719

13. Yu D, Zhang Y, Liu B (2008) Interpolyelectrolyte complexes of anionic water-soluble conjugated polymers and proteins as platforms for multicolor protein sensing and quantification. Macromolecules 41:4003-4011

14. Anant P, Lucas NT, Jacob J (2008) A simple route toward the synthesis of bisbenzothiadiazole derivatives. Org Lett 10:55335536

15. Xu S, Liu Y, Li J, Wang Y, Cao S (2009) Synthesis and characterization of low-band-gap conjugated polymers containing phenothiazine and benzo-2,1,3-thia-/seleno-diazole ( $\mathrm{p} \mathrm{n/a).} \mathrm{Polym}$ Adv Technol. doi:10.1002/pat.1487

16. Witker D, Reynolds JR (2005) Soluble variable color carbazolecontaining electrochromic polymers. Macromolecules 38:76367644

17. Kong X, Kulkarni P, Jenekhe SA (2003) Phenothiazine-based conjugated polymers: synthesis, electrochemistry, and lightemitting properties. Macromolecules 36:8992-8999

18. Luo J, Li X, Hou Q, Peng J, Yang W, Cao Y (2007) Highefficiency white-light emission from a single copolymer: fluorescent blue, green, and red chromophores on a conjugated polymer backbone. Adv Mater 19:1113-1117 